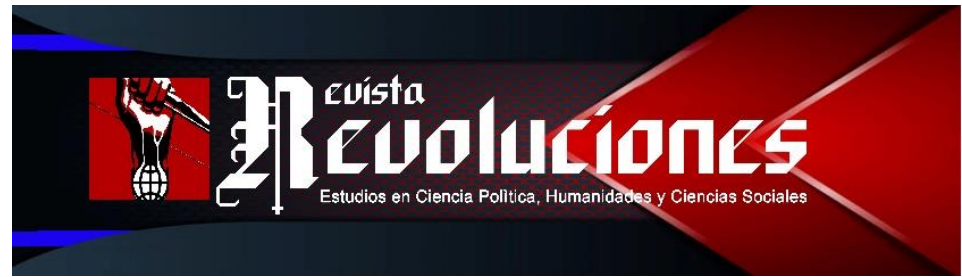

\title{
MUJERES EN LA PRENSA HISPANOAMERICANA EN TIEMPOS DE REVOLUCIÓN: LOS CASOS DE LIMA, CARACAS, BUENOS AIRES Y SANTIAGO DE CHILE
}

\author{
Women in the Hispanic American Press in Times of Revolution: The Cases of \\ Lima, Caracas, Buenos Aires, and Santiago de Chile
}

\section{Monserratt Rivera ${ }^{1}$}

UNIVERSIDAD NACIONAL MAYOR DE SAN MARCOS

PERÚ

maria.rivera23@unmsm.edu.pe

https://orcid.org/oooo-0003-4377-5511
Daniel Morán Ramos ${ }^{2}$

UNIVERSIDAD SAN IGNACIO DE LOYOLA

PERÚ

lmoran@usil.edu.pe

https://orcid.org/oooo-0002-8244-5390

DOI: https://doi.org/10.35622/j.rr.2021.05.006

Recibido: 01-VI-2021 / Aceptado: 20-VII-2021 / Actualizado: 29-VII-2021

\section{Resumen}

En vísperas del bicentenario del Perú y la relevancia actual que han adquirido los estudios de género, creemos conveniente poner en evidencia el rol que asumió la prensa escrita durante las guerras de independencia llevadas a cabo en los virreinatos hispanos. Específicamente se abordarán los casos de Lima, Buenos Aires, Caracas y Santiago de Chile. En este sentido, podremos observar cómo los periódicos de la época se alinean en distintos bandos (ya sea realista o patriota) y haciendo uso de su influencia en la población, ponen de manifiesto sus posturas respecto a la educación femenina y al rol que debía desempeñar el bello sexo durante las luchas patrióticas. Esto formaba parte de una estratagema política para ejercer un control social, en el cual los beneficiados eran los grupos de poder.

Palabras Clave: Prensa, Hispanoamérica, independencia, participación femenina, visión de la mujer.

\footnotetext{
${ }^{1}$ Estudiante de Historia de la Facultad de Ciencias Sociales de la Universidad Nacional Mayor de San Marcos, Perú. Su campo de investigación abarca la historia de género y la participación de la mujer en el siglo XIX.

${ }^{2}$ Docente Investigador de la Facultad de Educación en la Universidad San Ignacio de Loyola y Docente de Historia en la Facultad de Ciencias Sociales en la Universidad Nacional Mayor de San Marcos (Perú). Actualmente Investigador Renacyt (Carlos Monge, Nivel III) en CONCYTEC-Perú. Además, coordinador del Grupo de investigación Educación y Sociedad en el Perú y América Latina en la Facultad de Educación de USIL. Ha sido becario Roberto Carri (2009-2010) y becario doctoral del Instituto Ravignani de la UBA por el CONICET-Argentina (2011-2016). Doctor en Historia en la Universidad de Buenos Aires (Argentina), Magister en Historia en el Instituto de Altos Estudios Sociales de la Universidad Nacional de San Martín (Argentina) y Licenciado en Historia en la Universidad Nacional Mayor de San Marcos (Perú).
} 


\begin{abstract}
On the eve of Peru's bicentennial and the current relevance that gender studies have acquired, we believe it is convenient to highlight the role played by the written press during the wars of independence carried out in the Hispanic viceroyalties. Specifically, the cases of Lima, Buenos Aires, Caracas and Santiago de Chile will be addressed. In this sense, we will be able to observe how the newspapers of the time aligned themselves on different sides (either royalist or patriot) and, making use of their influence on the population, made clear their positions regarding female education and the role that the fair sex should play during the patriotic struggles. This was part of a political stratagem to exercise social control, in which the beneficiaries were the power groups.
\end{abstract}

Keyword: Press, Hispanic America, Independence, female participation, vision of the woman.

\title{
INTRODUCCIÓN
}

La prensa desde su aparición en la sociedad ha sido determinante en las coyunturas acaecidas en distintos países, puesto que tiene una influencia considerable en la opinión pública, llegando incluso a moldear el pensamiento de los ciudadanos. Esta situación no es ajena a las luchas independentistas en Hispanoamérica, vemos cómo distintos periódicos eligen bandos a los cuales apoyar y tratan de modificar el pensamiento de un grupo social para contribuir a la causa que defienden la prensa escrita.

De esta manera, surgen periódicos que pretender influenciar el actuar de la mujer con respecto a la lucha por la independencia, unos buscaban encarecidamente que el bello sexo adaptara a sus acciones el convencimiento de sus esposos para desistir en su búsqueda de la emancipación de la corona española y sobre todo el rechazo a las Juntas de Gobierno; mientras que, otros tenían como objeto que se educara a la mujer para que esta forme ciudadanos cultos que persigan la libertad. Los primeros tenían un claro tinte realista y los segundos se ubicaban en el bando patriota.

Respecto a la importancia de la prensa en aquel proceso, González sostiene que "se convertirá rápidamente en uno de los principales medios de propaganda de las ideas emancipadoras". Además, en los años que corresponden al periodo 1810-1825 surgen varios periódicos, algunos de ellos de tinte oficialista o realista, pero la mayor parte de los periódicos que aparecen en el mencionado periodo, sirvieron "como vehículo expresión de las ideas emancipadoras y que, una vez lograda la autonomía, contribuirían a la construcción del nuevo orden político.” (2011, p.57)

Por otro lado, García López señala que para realizar este tipo de investigaciones es necesario unir tres elementos que históricamente han estado separados, haciendo referencia a la mujer, medios de comunicación (en este caso la prensa escrita) y la independencia. Asimismo, explica que esta separación histórica se debe a que la prensa y la lucha por la independencia 
pertenecieron al espacio público, mientras que la mujer era la representante del ámbito privado. (2011, p.34)

No obstante, el hecho de que las mujeres fueran confinadas al ámbito privado, no impidió que tuviera protagonismo en la independencia que se gestaba, ya que el bello sexo logró transgredir las barreras sociales existentes y tomó un rol activo. Sin embargo, este cambio no permaneció en el tiempo dado que la prensa manipuló y minimizó su actuación, teniendo como resultado el olvido de su aportación a las luchas por la libertad. (García López, 2011, p.33). Entonces, se hace notable el rol que desempeñó la prensa en este contexto.

Asimismo, Morán y Aguirre refuerzan la idea del papel fundamental que jugó la prensa, no solo al funcionar como vehículo de información, sino que también fue una tribuna de debate ideológico que permitía que ciertos discursos tuvieran mayor alcance al ser publicados en áreas de mayor circulación. Para este fin, la prensa tuvo ayuda de distintas redes y espacios públicos como parques, plazas, mercados, chicherías, mesa familiar, teatros, café, tertulias, corridas de toros, juegos, procesiones religiosas y en el púlpito y en el altar por medio de los persuasivos sermones que los religiosos brindaban a sus seguidores. (2015, p.22)

De este modo, el presente artículo pretende profundizar en el conocimiento de los escritos de periódicos del siglo XIX relacionados a la educación del bello sexo y a la visión que se tenía respecto al papel que debían asumir en épocas de revolución. Por lo tanto, el objetivo general del presente texto es analizar fragmentos de las publicaciones realizadas por periódicos de la época emancipadora en ciudades específicas como Lima, Caracas, Buenos Aires y Santiago de Chile. De acuerdo a esto, se logrará reconocer el rol determinante que ejerció la prensa en la opinión pública.

\section{DESARROLLO}

\section{Lima}

En este acápite, expondremos algunos fragmentos de diversos periódicos de la época analizada. De tal manera, nos estaremos valiendo de impresos que circularon en el Perú, específicamente en Lima, por lo cual utilizaremos a La Gaceta de Lima, La abeja republicana, El Diario Secreto de Lima, entre otros. En suma, en este apartado del texto se tendrá como objetivo reconocer cómo "la prensa configuró la imagen de las mujeres y la educación femenina en el Perú" (Morán y Aguirre, 2015, p.57). Asimismo, podremos advertir la importancia de la participación del género femenino en el proceso independentista.

Por un lado, encontramos periódicos que manifestaban un claro apoyo a la política virreinal, dado que buscaban que las mujeres les sean útiles en la medida de que pudieran convencer a sus esposos de no involucrarse en la revolución independista y, por supuesto, que ellas se mantuvieran alejadas del mismo asunto. En este sentido, La Gaceta limeña expresa: "Nacidas para suavizar las costumbres del hombre, no deben tomar una parte activa en las 
discusiones, cuyo ardor es incompatible con la ponderación y dulzura que forman el embeleso de su sexo" (La Gaceta de Lima, no 22, 11 junio 1794, p. 299).

Entonces, es evidente la forma en la cual ejercen su influencia en un determinado sector de la población, específicamente en los sectores más conservadores, en los cuales las mujeres simplemente formaban parte del ámbito privado. Además, se hace notoria la forma en que les atribuyen ciertas características como "dulzura”, con lo cual pretenden convencerlas que, de llegar a levantarse en armas, estarían yendo contra su propia naturaleza; vale decir una naturaleza que los hombres decidieron asignarles.

Por otra parte, también se manifestaron periódicos a favor de la participación de las mujeres en la independencia, en el sentido de que ellas tenían como tarea principal formar a los futuros ciudadanos que lucharían por la libertad de su patria. Por este motivo, buscaban que las mujeres sean educadas: “fomentar la ilustración del bello sexo porque ellas eran las encargadas de educar desde el nacimiento y a través de todo el desarrollo de los niños hasta verse convertidos éstos en ciudadanos de provecho. Se insiste en las inclinaciones subyacentes de las mujeres, futuras esposas y madres, entregadas a las modas, las diversiones y las frivolidades nocivas a las buenas costumbres y a la educación de los hijos”. (El Investigador $\mathrm{n}^{\circ} 39,8$ de agosto de 1813).

Asimismo, sobre la importancia de la educación del bello sexo en el Perú, Los Andes libres agregan: "Grande es el interés que tiene el Estado en fomentar para las mujeres una educación metódica y virtuosa; pues que la naturaleza ha puesto a su cargo el de formar nuestras primeras ideas”. Además, señalaron que mientras más aceptación tengan las mujeres en los asuntos de la patria, más cultos eran los pueblos, por lo tanto, tomaban mejores decisiones. (Los Andes Libres $\mathrm{n}^{\circ}$ 11, 26 de octubre de 1821).

Igualmente, no solo se hacía un llamado al colaboracionismo femenino en la independencia por el simple hecho de formar a los futuros ciudadanos desde el nacimiento, sino que también se buscaba su apoyo en su condición de esposas: "Esposas tiernas, inspiraréis el sagrado amor de la Patria en los pechos de vuestros maridos; y seréis, con la imperiosa influencia de vuestras almas, nuestras segundas libertadoras. Madres virtuosas, prepararéis los héroes que han de sostener nuestros derechos, y ciudadanas de un país libre, emulareis nuestras glorias" (Los Andes Libres $\mathrm{n}^{\circ}$ 11, 26 de octubre de 1821).

No obstante, el hecho de buscar una educación apropiada para las mujeres de la época, para algunos significaba el mantenimiento del orden virreinal, puesto que se las educaría con ese propósito con el fin de que se lo transmitan a sus hijos. Así que se trata de un arma de doble filo: las educaban con el fin de formar una conciencia libertaria o buscar mantener el orden actual de la época, sea cualquiera de estas opciones, podemos notar la influencia de las mujeres en aquellos asuntos. Evidentemente, para un periódico que se encargaba de difundir y apoyar la política del virrey Abascal, como El Investigador la segunda opción era la indicada: "las modas, las diversiones, el paseo, frivolidades nocivas a las buenas costumbres

Revista Revoluciones $\mathbf{- 7 6}$ - Vol. $3, \mathrm{~N}^{\circ} 5$ (2021), pp. 73-87

Esta obra está bajo una licencia internacional Creative Commons Atribución 4.0. 
son las ocupaciones previas de las que destina la naturaleza para esposas y madres. ¿Cómo formarán ciudadanos de provecho, y buenas madres de familia las que no pueden dar a sus hijos las nobles ideas y sentimientos que no adquirieron ellas mismas? (El Investigador $\mathrm{n}^{\circ} 39$, 8 de agosto de 1813).

Asimismo, se consideraba parte importante de la educación a los niños también, obviamente con la ayuda de la iglesia católica:" Es necesaria la educación del bello sexo y de los niños, aprovechando las propiedades de la abolida Inquisición y la ayuda eficiente del clero religioso." (El Investigador $\mathrm{n}^{\circ} 61,30$ de agosto de 1813). Sin embargo, no funcionaba del mismo modo para todos los periódicos ya que, al sustentar la importancia de la educación, algunos se olvidaban de mencionar a las mujeres: "el más ínfimo de nuestros conciudadanos, el pobre artesano, el indio infeliz, el triste negro, el pardo, el ignorante, todos serán objeto de nuestras tareas. A todos queremos hablar e instruir, porque todos tienen derecho de oír y ser instruidos" (El satélite del peruano, febrero de 1812). Además, vale resaltar que se hacía un llamado a que el mismo pueblo se eduque: "pueblo: ilústrate, ilústrate, conocerás por ti mismo las farsas y las comedias sin necesidad de censores" (La abeja republicana $\mathrm{n}^{\circ} 31,17 \mathrm{de}$ noviembre de 1822)

Por otro lado, muchos de los periódicos de la época coincidían en que el tema de la libertad era un asunto que se conversaba todos los días en distintos espacios públicos: "Por todas partes no se oye otra cosa que libertad, seguridad e independencia. En no pocos países estas palabras se repiten en las conversaciones familiares, y aun por el bello sexo, en los púlpitos, en el foro, y en los papeles públicos" (La abeja republicana $\mathrm{n}^{\circ} 13,15$ de setiembre de 1822). El Diario Secreto de Lima agrega: "la voz de independencia y libertad es el voto del pueblo; ella es el objeto favorito de las conversaciones" (El Diario Secreto de Lima ${ }^{\circ}$ 9, 27 de febrero de 1811).

Uno de los escritos más resaltantes fue el realizado por López Aldana en el año 1811, en el cual hace un llamado a la educación femenina donde lo más importante que señala es que la naturaleza hizo a los hombres y mujeres semejantes, por lo cual ellas también tendrían un rol importante de conseguirse la tan ansiada libertad. De este modo, nos encontramos ante la importancia política que adquiere la mujer en este contexto.

"Hermanas de Lima: mujeres amables, sexo encantador: vosotras que amáis deliciosamente nuestra sociedad y nuestras conversaciones. ¿QQueréis tener esposos felices y distin-guidos con empleos? ¿Queréis que vuestros hijos sean bien educados, y que tengan destinos en que ejercitarse con honor y utilidad? Pues exige siempre de vuestros esposos y apasionado que os lleven algún papel importante de nuestra revolución: y que os juren todos sacrificarse por la libertad de Lima. Haced que en vuestras tertulias no se trate de otra cosa que de nuestra reunión a un solo fin, y de imitar a los americanos que por todas partes nos rodean, nos piden, nos instan, nos estrechan, a que sigamos sus heroicos pasos. ¿No sería mejor para vosotras que gobiernen en Lima vuestros propios paisanos, que no un godoista, o un francés? Suscribíos a mi diario graciosas limeñitas, y todas las lindas que habitáis esta ciudad, haciendo que vuestros conocidos lo copien y lo lean, de la propia suerte que todos los demás papeles, que respiren el dulce fuego de la libertad. Tened presente, que en el nuevo gobierno, vosotras habréis de tener también una

Revista Revoluciones $=77$ - Vol. 3, No 5 (2021), pp. 73-87

Esta obra está bajo una licencia internacional Creative Commons Atribución 4.0. 
gran parte, pues la naturaleza os ha concedido los mismos derechos en la sociedad que a los hombres" (El Diario Secreto de Lima ${ }^{\circ}$ 3, 6 de febrero de 1811).

Entonces, con todo lo expuesto anteriormente, se puede visibilizar la importancia de la prensa dentro de la aceptación de la participación de la mujer en los asuntos de revolución. Tanto como formadora de las ideas libertarias en sus hijos y la influencia que debían ejercer sobre sus esposos. Ya que, como señaló Los Andes libres, no podía ser posible que una mujer que aún "conservaba los vicios de una educación servil y descuidada", guíe a los suyos en la carrera hacia la libertad. (Los Andes Libres $\mathrm{n}^{\circ}$ 11, 26 de octubre de 1821). En suma, se trata de la "imagen determinante de las mujeres en los asuntos políticos como formadoras de ciudadanos y de hombres respetuosos de las autoridades legítimas". (Morán y Aguirre,2015, p.59)

Sin embargo, la presencia femenina no solo era requerida en los asuntos beneficiosos colectivos como las luchas independentistas, sino que también muchas veces las mujeres jugaron un rol oscuro en los asuntos políticos, y eso queda puesto en evidencia en La Abeja Republicana, que en aquel momento se encargó de elaborar una campaña de crítica a la labor represiva de Monteagudo: "colocó un crecido número de espías tanto de hombres como de mujeres que observaban la conducta de los patriotas, y que eran desterrados a Chile aquellos que eran contrarios al gobierno monárquico", entre estos espías se veían, "a muchos indignos ministros del altar, y demás innumerables hombres y mujeres que de noche entraban disfrazados en casa de Monteagudo, para darle noticia de lo acaecido en el resto del día" ( $L a$ Abeja Republicana $\mathrm{n}^{\circ}$ 7, t. 3, 7 de junio de 1823).

En conclusión, las mujeres son puestas en la escena política mediante la prensa escrita de la época, cada una de acuerdo a sus lineamientos; es decir, si un periódico estaba a favor de la continuidad del virreinato, se manifestaba como un seguidor de la participación femenina en la medida en que el bello sexo le sirva al virreinato para efectuar un control social. Como segunda conclusión, podemos establecer la necesidad de la prensa de difundir la relevancia de la educación en las mujeres, tanto para favor ciudadanos de bien, como para alentar a sus maridos, ya sea a luchar por la independencia o el mantenimiento del virreinato. Y por último, es importante señalar que las mujeres no solo sirven a las buenas causas, sino que también podían tener un lado oscuro, como las espías de Monteagudo.

\section{Caracas}

Para el caso de la mujer caraqueña, encontramos similitudes con lo realizado por la prensa peruana en Lima, en la manera de convocar a las mujeres a ser partícipes de las luchas por la Independencia de su país. Del mismo modo que en Lima, en Caracas también existieron periódicos a favor del régimen virreinal, mas no por esto, en sus publicaciones buscaban opacar al bello sexo, sino que todo lo contrario. La Gaceta de Caracas, periódico pro realista, convocó a las mujeres (además de los hombres, claro está) para que pudieran involucrarse en la producción literaria de los periódicos: "Se suplica por tanto a todos los Sujetos y Señoras, que por sus luces e inclinación se hallen en estado de contribuir a la instrucción pública, y a

Revista Revoluciones -78- Vol. 3, No 5 (2021), pp. 73-87

Esta obra está bajo una licencia internacional Creative Commons Atribución 4.0. 
la inocente recreación que proporciona la literatura amena, ocurran con sus producciones, en prosa o verso, a la oficina de la imprenta, situada en la Calle de la Catedral, del lado opuesto a la Posada del Ángel; y se ofrece corresponder a este favor empleando el mayor cuidado y prontitud en el despacho"(Gaceta de Caracas, 24 de octubre de 1808). Entonces, observamos que hubo una convocatoria para las mujeres, mediante la cual podían ser parte de la vida pública al igual que los hombres de su época.

Asimismo, contamos con la contribución de uno de los grandes impulsores de la independencia en el continente, Francisco Miranda, quien fundó el periódico El Colombiano. Gonzáles San Ruperto (2011) nos señala que aquel periódico tenía como objetivo principal ser distribuido en América y que, logró ejercer una influencia significativa en los criollos venezolanos. Si bien, no nos habla exactamente de una reivindicación de las mujeres en el plano político y su participación en las luchas independentistas; gracias a ese periódico, podemos advertir la relevancia de la prensa en los grupos sociales que buscaban una emancipación de la corona española.

Por otro lado, volviendo nuevamente a la Gaceta de Caracas, encontramos interesante un fragmento del año 1811, en el cual las mujeres piden entrar en la guerra a favor de la libertad: "El sexo femenino, Señor, no teme los horrores de la guerra: el estallido del cañón no hará más que alentarle: su fuego encenderá el deseo de libertad, que sostendrá a toda costa en obsequio del suelo Patrio. En esa virtud y deseando alistarse en el servicio para suplir el defecto de los militares que han partido a San Fernando, suplican a V.E se sirva tenerlas presente y destinarlas a donde le parezca conveniente bajo el supuesto de que no omitirán sacrificios que conciernan a la seguridad y defensa" (Gaceta de Caracas, 5 de noviembre de 1811).

Además, García López (2011) sostiene que existieron muchas menciones femeninas en la prensa de aquel tiempo, en los cuales se puede resaltar su participación activa dentro del dicho proceso, ya sea conspirando como espías, organizándose en tertulias. Igualmente, señala que las mujeres hacían uso de su supuesta debilidad y desinterés por la política para pasar desapercibidas y poder tener una mejor organización de las acciones a llevar a cabo. (p.37). No es para nada una sorpresa saber que muchas mujeres fueron capturadas mientras ejercían esas labores y fusiladas como castigo por conspirar contra el rey de la metrópoli española. Algunas de las acciones por las que fueron juzgadas son:

(...)la propagación de las ideas patriotas y la persuasión entre los ejércitos realistas (algunas fueron acusadas y hasta fusiladas por seducir a las tropas realistas para que se incorporasen al bando independentista), por la redacción de idearios y manifiestos, contribuyendo con la donación de dinero y joyas para la causa independentista, brindando refugio a los insurgentes, realizando el transporte de alimentos, ropas y material bélico, dedicándose a la reparación de armas, asumiendo el sustento familiar ante la ausencia de los hombres integrantes de las tropas insurgentes, con la presencia en los campamentos (troperas, rabonas, guareñas, soldaderas), ocupándose de la logística, acompañando a las tropas, preparando los avituallamientos, cocinando, atendiendo a los heridos, enterrando a los muertos, portando las armas, luchando 
como miembros de las guerrillas patriotas o como soldados en los campos de batalla, algunas vestidas de hombre para ser aceptadas en el combate, otras ejerciendo su condición de mujeres guerreras, desempeñando rangos militares e interviniendo como estrategas. (García López,2011, p.37)

En suma, se puede evidenciar la participación activa del bello sexo en gran parte del continente, por no decir en todas partes del continente. Vemos cómo incluso reclamaban para que se piense en ellas como soldados y no solo servir desde el ámbito privado. Además, también se puede notar cómo la prensa pudo haber influido positivamente en ellas al formarles una conciencia de libertad y sobre todo, brindarles el espacio que necesitaban para que todos los que pudieran acceder a los periódicos supieran que ellas también estaban luchando por su emancipación. En el caso de la prensa caraqueña, no hemos podido observar el discurso de la prensa de Lima, el cual pretende hacer uso de las mujeres en dicho contexto para influenciar sobre sus maridos y su posición respecto a la Independencia, o incluso no se habla de ellas relacionadas a su función de madres y formadoras de los futuros ciudadanos, vemos cómo se enfocan más en ellas mismas y su espíritu de lucha.

\section{Buenos Aires}

Para el caso de la prensa bonaerense del siglo XIX estaremos analizando los siguientes periódicos: El Correo de Comercio (1810-1811), La Gaceta de Buenos Aires (1810-1816) y El Observador Arnericano (1816). El segundo de estos, en uno de sus escritos nos advierte sobre la importancia de la circulación de periódicos y el impacto positivo sobre la población que podía acceder a los mismos: "en los pueblos libres todos leen, todos meditan y reflexionan en círculos y conversaciones familiares acerca de lo que se dice, anuncia y discute en los periódicos" (La Gaceta de Buenos Aires nº 20, 9 de septiembre de 1815).

Es resaltante el caso de un periódico en el cual las mujeres se refieren a su actividad de lectura, llegando incluso a pactar días para realizarla de manera colectiva, además el mismo artículo hace referencia a la necesidad de una educación para el bello sexo: "En una sociedad de amigas hasta entonces sin título oímos leer el primer número del nuevo periódico intitulado El Observador Americano, y el interés propio llamó nuestra particular atención el artículo Educación de las mujeres. [...] continuó la conversación [...] Esta se redujo a que todos los lunes nos reuniríamos en el mismo lugar para leer el Observador" (El Observador Americano $\mathrm{n}^{\mathrm{o}} 7,30$ de septiembre de 1816).

Asimismo, al igual que en el caso limeño, la educación femenina era requerida en le medida que forme a los futuros ciudadanos desde el nacimiento, es decir, la educación del bello sexo se fundamentaba en base a su futuro rol de madre: El bello sexo debía ser educado durante la revolución desde la esfera del poder porque "uno de los objetos de la política es formar las buenas costumbres en el Estado" y más aún si en aquella coyuntura "el bello sexo que principalmente debe estar dedicado a sembrar las primeras semillas lo tenemos condenado al imperio de las bagatelas, y de la ignorancia" (Correo de Comercio, Buenos Aires n ${ }^{\circ} 21,21$ de julio de 1810). Como podemos observar en dicha cita, la frase "sembrar primeras semillas", hace referencia al rol de madres ejercido por el bello sexo. 
Del mismo modo, un fragmento del Correo de Comercio refuerza lo dicho anteriormente, ya que menciona que las escuelas para mujeres debían dedicarse a formar buenas madres: Estas escuelas del bello sexo debían "ser el vivero de las buenas madres, buenas hijas de familia, buenas maestras para las escuelas", con lo cual se podía permitir, "abrir el camino a las buenas costumbres, y generalizarlas de un modo uniforme" (Correo de Comercio, Buenos Aires $n^{\circ}$ 22, 28 de julio de 1810).

Sin embargo, al igual que en los otros casos, estos periódicos también utilizaban su influencia para que las mujeres pudieran convencer a sus esposos de no involucrarse en las luchas independentistas, especialmente de las Juntas que se formaron en el continente: "Y tú, sexo delicado: tú, a quien la providencia encargó de suavizar la aspereza del hombre, inspira con tus encantos la mansedumbre de tu carácter" (Anónimo, 1810, p. 11). Incluso, mencionaba ejemplos de lo mal que podía terminar su situación si seguían involucrándose en las juntas: "Mira las funestas escenas de la Francia y los horrores de Santo Domingo, y en la suerte del infeliz Buenos Aires mira el trágico fin de las Juntas" (Anónimo, 1810, p. 12). Cabe recalcar que la persona que redactó tal exhortación, no firmó con su nombre. Asimismo, se resalta la importancia femenina en la vida del hombre desde su nacimiento: "Débiles y estúpidos en la infancia, incautos y desprovistos en la puerilidad nuestra existencia seria precaria sobre la tierra sin los auxilios de este sexo delicado" (La Gaceta de Buenos Aires n ${ }^{\circ}$ 14, 20 de diciembre de 1811).

Al contrario de la dicha exhortación, otros periódicos se encargaron de abogar en favor de la mujer y su capacidad de participar en el proceso independentista: "las mujeres tienen espíritu, y aunque se las ha pretendido siempre entretener en la frivolidad y bagatela, cuando tratan de asuntos serios descubren los quilates de su talento y generosidad" (La Gaceta de Buenos Aires n 40, 14 de marzo de 1811). Además, se manifestaron en La Gaceta de Buenos Aires, afirmando que las juntas no se disolverían: "Nuestro sexo ha dado ya en este continente repetidas pruebas de su valor y talento [...] Piensa este badulaque deshacer las juntas ya instaladas con su miserable folleto ¿Cree que tantos pueblos, que logran ser gobernados por sus naturales, volverán a someterse a la tiranía de los sátrapas, que los saqueaban en fuerza de las reflexiones filantrópicas?" (La Gaceta de Buenos Aires n 40, 14 de marzo de 1811).

Entonces, como ya resulta evidente, el rol desempeñado por la mujer en el proceso revolucionario no estaría ligado únicamente a su función de madre, esposa y formadora de futuros ciudadanos, sino, también habría contribuido a la lucha revolucionaria participando activamente en el debate doctrinario y en las determinaciones políticas de la coyuntura. (Morán y Aguirre, 2015, p.85) Ya que, se conoce que eran activas participantes de las tertulias que, muchas veces, ellas mismas organizaban, como la que se difundió el periódico $E l$ Observador Americano: Incluso, en una carta enviada al periódico se informó la formación de una tertulia femenina con el nombre de Sociedad del Observador Americano, con el claro objetivo de leer y debatir sus ideas pedagógicas y políticas (El Observador Americano, Buenos Aires $n^{\circ}$ 7, 30 de septiembre de 1816). 
Para agregar, la prensa no solo resaltó la participación de las mujeres que transgredían el orden social establecido, es decir, quienes participaron políticamente en el debate de ideas, sino que también hicieron énfasis en las labores más "permitidas" en una mujer dada la época:" Pero en nuestra revolución han tenido las mujeres una parte principal. [...] Muchas Señoras han manifestado el más vivo interés de contribuir al alivio, y comodidad de los soldados, que combaten por la salud, y el amor de su patria en aquellas labores, que son compatibles con la delicadeza del bello sexo" (La Gaceta de Buenos Aires n 72,24 de octubre de 1811). Al mencionar "labores compatibles" hace referencia a las acciones que si eran bien vistas en el bello sexo, es decir, labores de enfermería, costura de los uniformes de los soldados, recolección de víveres, entre otras acciones que no les quitaran protagonismo a sus compañeros del sexo opuesto.

La Gaceta de Buenos Aires resalta la importancia de haber inspirado el patriotismo en las mujeres y el hecho de que ellas tuvieran la capacidad de propagarlos mediante otros recursos como cantos, con los cuales su poder de convencimiento se incrementó. También, podemos señalar sobre el siguiente fragmento que, La Gaceta de Buenos Aires hace una distinción entre los héroes de la patria y las mujeres, olvidándose así de las valientes guerreras que participaron tomando las armas:

\begin{abstract}
"Unos de los medios de introducir las costumbres, fomentar la ilustración en todos sus ramos, y sobre todo estimular, y propagar el patriotismo es que las señoras americanas hagan la firme y virtuosa resolución de no apreciar, ni distinguir mas que al joven moral, ilustrado, útil por sus conocimientos, y sobre todo patriota, amante sincero de la LIBERTAD, y enemigo irreconciliable de los tiranos. Si las madres y esposas hicieran estudio de inspirar a sus hijos, maridos, y domésticos estos nobles sentimientos, y si aquellas [...] emplearan el imperio de su belleza y artificio natural en conquistar desnaturalizados, y electrizar a los que no lo son ¿qué progresos no haría nuestro sistema? Sabemos que en las grandes revoluciones de nuestros días el espíritu público y el amor a la LIBERTAD han caracterizado dos naciones célebres, aunque no igualmente felices en el suceso, debiéndose este efecto al bello sexo que por medio de cantos patrióticos y otros insinuantes recursos inflamaba las almas menos sensibles, y disponía a los hombres libres a correr gustosos al patíbulo por sostener la majestad del pueblo. [...] al lado de los héroes de la patria mostrara el bello sexo de la América del Sud el interés con que desea ver espirar al último tirano, o rendir el supremo aliento antes que ver frustrado el voto de las almas fuertes" (La Gaceta de Buenos Aires nº 14, 20 de diciembre de 1811).
\end{abstract}

En la misma línea que La Gaceta de Buenos Aires, otro periódico bonaerense llamado El Observador Americano, coincidía en la importancia para la patria que significaba la inserción de las mujeres en la educación, afirmando que era una de las causas del progreso de otros países en los cuales el bello sexo si tenía acceso a la ilustración: "en todos los países no es solamente el efecto sino una de las causas más principales de la civilización nacional, de su prosperidad, y de su poder" (El Observador Americano, Buenos Aires nº 1,19 de agosto de 1816). 
Para concluir con este acápite, sería atinado señalar que la prensa bonaerense manifiesta una aceptación para llevarse a cabo la educación femenina (al menos en los tres periódicos analizados en el presente texto), utilizando argumentos referidos a la prosperidad de otros países y a la formación de buenos y conscientes ciudadanos con ayuda de las madres educadas. Asimismo, es necesario indicar que las mujeres no estuvieron ausentes en el panel político del contexto del proceso independentista, dado que, fueron asiduas participantes y organizadoras de tertulias, donde debatían sus posturas políticas respecto a lo que sucedía en su territorio.

\section{Santiago de Chile}

Y como último apartado de este texto, contamos también con la presencia de la prensa chilena durante los tiempos de revolución en el continente americano con periódicos como La Aurora de Chile y El Monitor Araucano. En el primero de estos, se destaca, al igual que en los casos anteriores estudiados, la importancia de la educación en el contexto que se vivía. Haciendo énfasis en que no solo las élites debían tener acceso a la misma, sino también las clases populares e incluso las mujeres:

"No solamente los nobles y los ricos deberían ser doctrinados en estos principios, sino los plebeyos, los artesanos, los labradores y mucha parte de las mujeres. Si estas artes se difundieran de las capitales a las villas, y de estas a las aldeas, producirían los admirables efectos de dar a toda la nación un cierto aire de civilidad, y unas modales cultas; de introducir en las familias el buen orden y la economía; de corregir la educación, que por lo común se entiende mal; de modificar los ingenios de muchos, enseñándoles a hacer el uso que deben de los talentos que Dios les ha dado y, finalmente, de perfeccionar las artes, haciéndolas más expeditas, más comunes y más útiles" (La Aurora de Chile $\mathrm{n}^{\circ}$ 9, 9 de abril de 1812).

Asimismo, el mismo periódico refuerza su opinión respecto a la educación un mes después con lo siguiente: "Las obras sabias necesitan hallar en los pueblos una disposición feliz. ¿De qué sirve escribir, si la barbarie es tan grande, que no hay quién lea? Entonces la marcha de las luces se retarda, y el día dista mucho de la aurora. La ilustración debe hacerse popular, pero las instituciones antiguas fueron bien contrarias de la difusión de las luces. Las ciencias tratadas en latín es el mayor obstáculo que puede ofrecerse no solo a su difusión, sino también a su perfección. De aquí es que la ilustración es más general en los países que han desterrado esta práctica bárbara" (La Aurora de Chile $\mathrm{n}^{\circ}$ 13, 7 de mayo de 1812).

Como es perceptible, para La Aurora de Chile es totalmente necesaria una educación a la cual puedan acceder todos, tanto las clases altas como los sectores más pobres, además señalan que si, no hay nadie educado en el país, será imposible que la "luz" del conocimiento haga su trabajo en el progreso de la sociedad. Por añadidura, resaltan que el antiguo Gobierno tuvo como característica una desidia con respecto al sector educativo, en especial la educación brindada a las mujeres. Asimismo, hacen una crítica ligada a la gran cantidad de población residente en la capital chilena y la inexistencia hasta el momento de una escuela dedicada al bello sexo: 
"La indiferencia con que miró el antiguo Gobierno la educación del bello sexo, sino pudo ser un resultado del sistema depresivo, es el comprobante menos equivoco de la degradación con que era considerado el Americano: parecerá una paradoja en el mundo culto, que la capital de Chile poblada de más de cincuenta mil habitantes, no haya aun conocido una escuela de mujeres; acaso podría creerse a la distancia un comprobante de aquella máxima bárbara, de que el americano no es susceptible de enseñanza; pero ya es precise desmentir errores, y sobre todo dar ejercicio a las claros talentos del sexo amable" (La Aurora de Chile $\mathrm{n}^{\circ}$ 29, 27 de agosto de 1812).

Dado lo expuesto anteriormente, estas opiniones de La Aurora de Chile coinciden con lo expuesto por el periódico limeño El Investigador del Perú, el cual señala que, si una mujer no está educada, en cuanto tenga la posibilidad de ser madre no podrá formar ciudadanos de bien ya que ella no adquirió esos conocimientos anteriormente. En ese sentido, ambos periódicos sintonizan su postura respecto a una educación femenina. Por otro lado, $E l$ Monitor Araucano nos habla acerca de la importancia de la libertad de prensa y la conciben como un derecho en la medida que nos aporta conocimiento: "La libertad de prensa y de la lectura es un derecho incontestable fundado sobre el derecho que tenemos a instruirnos [...] La libertad de discutir las materias ante el tribunal del público, y el choque de los discursos y de las opiniones, harán descubrir la verdad, y asegurarse de su evidencia”. (El Monitor Araucano, $\mathrm{N}^{\circ}$ 64, Santiago, 25 de julio de 1814)

Por último, La Aurora de Chile nuevamente hace hincapié en la intervención del Gobierno para asegurar una buena educación que sea difundida en las clases populares: "La rudeza de costumbres e ignorancia de las letras, no puede remediarse si no interviene el brazo poderoso del gobierno y toma a su cargo los primeros fundamentos de la reforma de las escuelas. Es notorio que son las opiniones las que dirigen a los pueblos, y que las escuelas son la cuna donde nacen y se alimentan las opiniones para difundirse después en la plebe". (La Aurora de Chile $\mathrm{n}^{\circ} 9$, 9 de abril de 1812)

Para concluir con el presente acápite, podemos notar que, a diferencia de la prensa de los otros territorios mencionados, los periódicos chilenos basaron sus escritos periodísticos generalmente en la discusión sobre la relevancia de la prensa en el proceso independentista que se gestaba, mas no en la participación femenina en el mismo o la influencia que estas tenían sobre sus esposos. Coincidiendo que esta educación no solo debía estar orientada a las élites, sino que también debía llegar a las clases populares, en especial importancia a las mujeres dado que ellas en su condición de madres formarían la conciencia de los futuros ciudadanos del país. Como comentario, me gustaría agregar que en el periodo estudiado no se observan numerosas menciones a la mujer en la independencia en su calidad de guerreras o espías, sino que más bien la discusión de la prensa está orientada a si el bello sexo debía frenar los impulsos de sus esposos de apoyar a las Juntas o si debía incitarlo a ello, resaltando cualidades en ellas como "dulzura" y sobre todo haciendo énfasis en que fueron creadas para suavizar los impulsos de los hombres. 


\section{CONCLUSIONES}

Por una parte, observamos como para el caso limeño, la prensa escrita adquiere influencia en la visión de la participación de las mujeres en el contexto revolucionario independentista, reforzando la idea de que el bello sexo tiene como función amansar el carácter del hombre. Esta última idea propulsada por La Gaceta de Lima. Mientras que, periódicos como $\mathrm{El}$ Investigador o Los Andes Libres centraban su atención en la búsqueda de una educación femenina de calidad, con el objetivo de preparar a las futuras madres, para que estas le entreguen al Estado buenos ciudadanos. Asimismo, otros periódicos hacían un llamado al pueblo en general para que tengan como objetivo educarse y "abrir los ojos" ante la situación que atravesaban.

En suma, la prensa limeña reconoce la importancia de la educación para todos los sectores y hace un énfasis especial en el bello sexo y, en algunos casos, también impulsa la búsqueda de una educación para los más jóvenes: los niños. A diferencia de los periódicos limeños, la prensa de Caracas realizó un llamado a las mujeres para que se involucren activamente en la causa independentista, no solo como formadora de los futuros ciudadanos o amansadora del carácter masculino, sino que fueron convocadas para escribir en los periódicos caraqueños. Esto último goza de gran relevancia puesto que constituye una invitación a formar parte de la vida pública, abandonando momentáneamente el ámbito de lo privado.

Asimismo, fueron importantes las menciones femeninas realizadas en los periódicos caraqueños, evidenciando que el bello sexo tuvo participación en la independencia de su país. Para el caso de Buenos Aires, se encuentran semejanzas con la prensa limeña en su discurso sobre la necesidad de la educación femenina con el mismo argumento utilizado por los limeños: formar a los futuros ciudadanos. Además, otra de las similitudes halladas se refiere a la influencia que tienen las mujeres sobre sus esposos, pidiendo que los convencieran de no involucrarse en las Juntas. Y lo más resaltante del caso bonaerense fue la carta enviada a $E l$ Observador Americano, en el cual un grupo de mujeres manifiesta su interés por participar en tertulias.

Por último, la prensa de Santiago de Chile coincide con Buenos Aires y Lima en la necesidad de la educación del bello sexo y la educación en general, como forma de combatir la barbarie y conseguir el progreso. Así también, es importante resaltar que promovían una educación que sea accesible tanto a las clases altas como a las bajas, y la importancia del Gobierno para que esta se lleve a cabo. Por último, hacen un importante aporte al defender la libertad de prensa. Como podemos observar, la prensa chilena no se expresó tanto en materia de la participación activa de las mujeres en la Independencia.

\section{REFERENCIAS BIBLIOGRÁFICAS}


Brewster, C. (2005). Capítulo 2. Las mujeres, la Guerra y la Independencia hispanoamericana en South American Independence: Gender, Politics, Text. Liverpool: Latin America Studie.

Brewster, C. (2005). Capítulo 6. Las mujeres, la Guerra y la Independencia hispanoamericana en South American Independence: Gender, Politics, Text. Liverpool: Latin America Studie.

Cruz-Reyes, V. (1994). Educación y papel de la mujer en el periodo de transición del siglo XVIII al XIX en Mesoamérica. Conferencia "Mujer, educación y feminismo". Universidad Pedagógica Nacional Francisco Morazán, Honduras.

Di Meglio, G. (2013). La participación popular en las revoluciones hispanoamericanas, 18081816. Un ensayo sobre sus rasgos y causas. Almanack. Guarulhos, n.05, p.97-122

Elejalde Jara, E. (2013). La representación de la mujer en la construcción nacional del Estado peruano a inicios del período independiente. Nueva Corónica, núm. 2, pp.313-331.

García López, A. (2011). La participación de las mujeres en la independencia hispanoamericana a través de los medios de comunicación. Historia y Comunicación Social, vol.16, pp.33-49.

García López, A. (s.f). Las olvidadas de la independencia hispanoamericana. Memoria, pp.1416.

García López, A. (s.f). Las heroínas calladas de la Independencia Hispanoamericana. Instituto Cervantes, en https://cvc.cervantes.es/literatura/mujer independencias/garcia.htm

González San Ruperto, M. (2011). La prensa en el proceso emancipador de la América española: Información, propaganda y formación. Historia y Comunicación Social, vol. 16, pp. 51-67.

Guardia, S. B. (ed.) (2014). Las mujeres en los procesos de independencia de América Latina. CEMHAL-UNESCO: Lima.

Gutiérrez Aguilera, M. (2014). Mujeres rioplatenses al servicio de la revolución: algunos aportes de ignoradas heroínas. Naveg@mérica. Revista electrónica editada por la Asociación Española de Americanistas, núm.12, pp.1-34.

Mannarelli, M. (2004). Sobre la historia de lo público y lo privado en el Perú desde una perspectiva feminista. Revista Iberoamericana, Vol. LXX, 141-156.

Morán Ramos, D. (2018). Las “jacobinas de la revolución”. Imágenes y representaciones de la mujer en la prensa de Buenos Aires (1810-1816). Tiempos Modernos, núm. 37, pp. 148-160.

Morán Ramos, D. \& Pérez Valdivia, J. (2020). De la revolución del impreso a la orgía periodística. Prensa y discurso político en la historiografía de la independencia del Perú. Tiempos Modernos, núm. 40, pp.295-311.

Morán Ramos, D. \& Pérez Valdivia, J. (2020). "No solamente los nobles y los ricos, sino los plebeyos y mucha parte de las mujeres". El discurso político de la prensa chilena sobre la educación popular durante la Patria Vieja (1812-1814). Cuadernos de Historia, núm. 53, pp. 229-253.

Morán, D. \& Aguirre, M. (2015). Prensa política y educación popular en la Independencia de América Latina. Colección Historia de la Prensa Peruana $\mathrm{N}^{\circ} 7$ : Lima. 
Navarrete Núñez, C. (2015). Comentario sobre Mujeres y revolución en la independencia de Hispanoamérica. Tzintzun. Revista de Estudios Históricos, núm. 62, pp. 362-368.

Ortemberg, P. (2011). Apuntes sobre el lugar de la mujer en el ritual político limeño: de actrices durante el virreinato a actoras de la independencia. Estudios Interdisciplinarios de América Latina y el Caribe, 22(1), pp. 105-128.

Penagos Carreño, J. (2012). La prensa en la Nueva Granada entre 1810 y 1812. ICANH, pp. $15-45$.

Reisz, S. (2015). El rol de las mujeres en la independencia del Perú. Discurso para el proyecto «Bicentenario: Camino a la libertad». Recuperado de https://docplayer.es/21879588El-rol-de-las-mujeres-enla-independencia-del-peru-susana-reisz-pucp.html

Román López, M., Cantos Casenave, M., Sánchez Hita, B. (2010). Mujer y Guerras de Independencia. Paralelismos entre la actitud de la mujer por la conquista de la opinión pública en España y América (1808-1814). Cádiz: Universidad de Cádiz.

Rosas Lauro, C. (ed.) (2019), Género y mujeres en la historia del Perú. Del hogar al espacio público. Lima: Fondo Editorial de la PUCP.

Rosas Lauro, C. (2007), Educando al bello sexo. La imagen de la mujer en el periodismo peruano del Siglo de las Luces (en prensa).

Salazar Rocuant, S. (2018). Tres mujeres de independencia, tres aportes distintos: la construcción del sujeto histórico femenino en la sociedad tradicional. Informe para optar al grado de Licenciado en Historia. Santiago de Chile: Universidad de Chile.

Terán, M. \& Gayol, V. (eds.) (2010). La corona rota: identidades y representaciones en las independencias iberoamericanas. Castelló: Universitat Jaime I.

Terán, M. \& Gayol, V. (2010). Las independencias hispanoamericanas. Representaciones, identidades y memoria. En La corona rota: identidades y representaciones en las independencias iberoamericanas. Castelló: Universitat Jaime I.

Valdivieso, M. (2009). Las mujeres y lo femenino en el discurso historiográfico: su contribución a la memoria y al imaginario social latinoamericano sobre la presencia de las mujeres en el espacio público. XII Jornadas Interescuelas, Departamentos de Historia, Departamento de Historia, Facultad de Humanidades y Centro Regional Universitario Bariloche. Universidad Nacional del Comahue, San Carlos de Bariloche.

\section{PRENSA}

El Diario Secreto de Lima [ Lima, Perú], 1811.

El Peruano [ Lima, Perú],1811.

El Satélite del Peruano [ Lima, Perú], 1812.

La Gaceta del Gobierno de Lima [ Perú], 1812.

El Investigador [ Lima, Perú], 1813.

El Investigador del Perú [ Lima], 1814.

Los Andes Libres [ Lima, Perú], 1821.

La Abeja Republicana [ Lima, Perú], 1822.

El Diario Secreto de Lima [ Perú], 1811.

Correo de Comercio [ Buenos Aires], 1810-1811.

Revista Revoluciones $\mathbf{- 8 7 -}$ - Vol. $3, \mathrm{~N}^{\circ} 5$ (2021), pp. 73-87

Esta obra está bajo una licencia internacional Creative Commons Atribución 4.0. 
El Observador Americano [ Buenos Aires], 1816.

La Gaceta de Buenos Aires [ Buenos Aires], 1810- 1816.

La Aurora de Chile [ Santiago de Chile], 1812-1813.

El Monitor Araucano [ Santiago de Chile], 1812.

La Gaceta de Caracas [ Caracas], 1811. 